\title{
Comparative study on the effects of low cost oil seed cakes and fish meal as dietary protein sources for Labeo rohita (Hamilton) fingerling
}

\author{
K.A. Latif ${ }^{1}$, M.T. Alam², M.A. Sayeed ${ }^{3}$, M. Afzal Hussain ${ }^{4}$, S. Sultana ${ }^{5}$ and M.A. Hossain ${ }^{4}$ \\ ${ }^{1}$ Department of Fisheries, Bangladesh; ${ }^{2}$ Institute of Biological Sciences, University of Rajshahi, Rajshahi; ${ }^{3}$ Department of \\ Biology and Genetics, Bangladesh Agricultural University, Mymensingh; ${ }^{4}$ Department of Fisheries, University of Rajshahi, \\ Rajshahi; ${ }^{5}$ Department of Zoology, University of Rajshahi, Rajshahi
}

\begin{abstract}
A trial was conducted to evaluate the effects of combination of soybean meal (SBN), mustard oilcake (MOC), sesame oilcake (SOC) and linseed oilcake (LOC) as alternative for dietary fish meal (FM) protein for Labeo rohita fingerling for a period of 56 days. Six experimental diets were formulated by replacing $30,50,60,70$ and $100 \%$ (2 diets) of the total dietary fish meal protein by the combination of FM, SBM, MOC, SOC, and LOC. The combinations of the protein sources were as diet 1 (FM 100\%), diet 2 (FM:SBM:MOC::70:15:15), diet 3 (FM:SBM:SOC:LOC::50:20:20:10), diet 4 (FM:SBM:SOC:LOC::40:20:20:20), diet 5 (FM:SBM:SOC:LOC::25:30:15:30), diet 6 (SBM:MOC:SOC:LOC::25:25:25:25) and diet 7 (SBM:SOC:LOC::40:30:30). The performances of these six test diets were compared with the diet 1 (control). All diets were iso-nitrogenous containing about $30 \%$ protein. The growth trial was conducted in a flow through system under laboratory condition with three replications for each treatment. On the basis of the growth response, food conversion ratio (FCR), protein efficiency ratio (PER) diet 7 showed better performance followed by diet 1, diet 2, diet 5, diet 3, diet 4 and diet 6 respectively but those were not significantly different $(\mathrm{P}>0.05)$. The diet 6 produced the lowest performance. The apparent protein digestibility (APD) values for all the experimental diets were very nearer but significantly different $(\mathrm{P}<0.05)$ and the values ranged from 70.55 to $77.79 \%$; diet 1 showed the highest APD $(77.79 \%)$, while diet 5 showed the lowest APD (70.55\%). The results indicated that there was no significant difference $(\mathrm{P}>0.05)$ in diets even from control one which were formulated to evaluate the effects of combination of low cost oil seed cakes as dietary protein source for Labeo rohita fingerling. Hence, it might be concluded that from the economic point of view, that all the low cost oil seed cakes which are locally available can be used in combination form as the alternative protein source for the feed of Labeo rohita.
\end{abstract}

Key words: Oil seed cakes, Labeo rohita, fingerling, protein source.

\section{Introduction}

To ensure the maximum production of fish, it is obligatory to produce suitable, complete and supplemental cost effective diets for use in hatcheries and nursery ponds. Cost effective but quality feed from indigenous ingredients will increase the quality of seed, which is the prerequisite to boost the aquaculture. Therefore studies to formulate suitable feeds for commercially important fish species would constitute an important area of research for the development of aquaculture in Bangladesh. Traditionally, fish meal has been used as the major source of dietary protein for fish and its fry throughout the world; but the scarcity and high price limits its utilization as the source of protein in Bangladesh (Hasan et al., 1997). Also due to the sufficient use of fish meal as in poultry and fish farming; it becomes hard to afford by nursery and hatchery owners. Therefore, it is very much necessary to find out alternative, cheap and locally available protein source for fish feed.

Soybean meal has been well documented as a potential fish meal alternate because of its high protein value (49.46\%) (Saad, 1979; Tacon et al., 1983;
Wassef, 1991; Reigh \& Ellis, 1992).Moreover, whole soybean contains quality oil, which is the source of fairly metabolizable energy. Raw soybean contains several anti-nutritional factors and other toxic substances, which can adversely affect the growth and well being of animals. In such a situation, after heating and grinding soybean to meal (Full-fat soybean mealFFSBM) have been used successfully in the diets of animals. Recently, research on the utilization of full-fat soybean meal by fish has undertaken.

It is very much essential to develop suitable complete, supplementary and economically cost effective diet for use in nursery pond. Soybean meal, mustard oil cake, sesame oil cake and linseed oil cake were used in combined form to evaluate as dietary protein sources for Labeo rohita fingerling. Though numerous workers using individually or with other carbohydrate rich ingredients evaluated all these ingredients previously, but the effects of combination of these oil cakes were not studied previously. For these purpose feed were formulated by using the square method and algebraic equation for balancing crude protein levels. The present investigation was 
undertaken to formulate several test diets for $L$. rohita fingerling by combining soybean meal, mustard oil cake, sesame oil cake and linseed oil cake and their trial under laboratory condition.

\section{Materials and Methods}

The study was carried out in a flow through system in the Dept. of Aquaculture, Bangladesh Agricultural University, Mymensingh for a period of 56 days during the month of September to November, 1999. Twenty one plastic buckets (containing about 17 litre water) were used for the experiment. The water supply for the continuous flow through system was continued from a deep tube well and supported by a centrifugal pump, which was agitated before being collected in 6 steel header tank. The collected fingerlings were acclimated to the laboratory condition for a period of 7 days. During acclimation, adequate oxygen was supplied, temperature was maintained from $28^{\circ} \mathrm{C}$ to $30^{\circ} \mathrm{C}$ and fish were fed twice daily with compounded pelleted feed containing 30\% protein. The fingerlings of rohu (mean weight $2.5 \pm .04 \mathrm{~g}$ ) were randomly distributed at a rate of 12 fish per bucket. Water was allowed to drop down into each bucket with a rate of $250 \mathrm{ml}$ per minute, which was increased up to $350 \mathrm{ml}$ per minute with the increase of fish size. Each bucket was covered by nylon net to prevent jumping out of fish. Siphoning was done to remove uneaten feed and faeces twice daily.

To prepare experimental diets different ingredients such as- fish meal (56\% protein), defatted soybean cake, mustard oilcake, sesame oilcake and linseed oilcake seed, cod liver oil and soybean oil, minerals and vitamin premix, carboximethyl cellulose, chromic oxide, $\alpha$-cellulose and wheat flour were collected. Prior to formulation of diets different ingredients (protein source) were subjected to proximate analysis (Table 1 and 2). Seven isonitrogenous diets were formulated to contain 30\% protein (Akand et al., 1991), 14-17\% lipid, 6 to $10 \%$ crude fiber (Jauncey \& Ross, 1982) and 31$35 \%$ digestible carbohydrate. Diets were formulated to be as iso-caloric as possible. During the formulation of diets essential fatty acid contents were taken into consideration by adjusting the level of cod liver oil and soybean oil.

For diet preparation all ingredients were ground finely and sieved. After sieving all the required amount of dry ingredients along with the vitamin, mineral premix and chromic oxide were weighed as per formula and mixed thoroughly (Table 3). During mixing the ingredients, soybean oil and cod liver oil were added and mixed thoroughly with the mixture to assure homogeneity. Required amount of water was added to make the mixture moisten. This resultant dough was then passed through a $1.0 \mathrm{~mm}$ diameter hand-pelleting machine. The resultant pellets were dried in an oven at $40^{\circ} \mathrm{C}$ for 24 hours. All the diets were separately stored in an airtight plastic container for further use. Seven different types of diets were prepared. The initial and final weights of the fish were recorded. Three replications were taken for each treatment.

Table 1. Proximate composition of the protein sources used in the experiment (\% dry matter basis).

\begin{tabular}{lcccccc}
\hline \multicolumn{1}{c}{ Protein sources } & Dry matter & Crude protein & Crude lipid & Ash & Crude fiber $^{\text {NFE }^{\mathbf{1}}}$ \\
\hline Fish meal & 85.56 & 56.28 & 16.55 & 21.28 & 5.19 & 0.70 \\
Soybean meal & 89.73 & 49.65 & 5.19 & 8.30 & 6.73 & 30.13 \\
Mustard oilcake & 87.00 & 33.54 & 19.82 & 6.55 & 14.94 & 29.01 \\
Sesame oilcake & 90.00 & 30.62 & 17.90 & 9.81 & 8.46 & 33.29 \\
Linseed oilcake & 88.97 & 30.09 & 25.17 & 7.19 & 6.78 & 28.57 \\
\hline NFE $^{1}$ = Nitrogen free extract calculated as 100 - \% (moisture +protein + lipid + ash + crude fiber). & \multicolumn{4}{c}{}
\end{tabular}

Table 2. Proximate composition of the experimental diets ( $\%$ dry matter basis).

\begin{tabular}{lccccccc}
\hline Component & \multicolumn{7}{c}{ Diet } \\
\cline { 2 - 8 } & 1 & 2 & 3 & 4 & 5 & 6 & 7 \\
\hline Dry matter & 94.61 & 93.30 & 94.24 & 93.61 & 94.10 & 93.42 & 93.14 \\
Crude protein & 31.13 & 33.01 & 32.09 & 32.82 & 32.15 & 32.49 & 31.66 \\
Crude lipid & 13.32 & 13.62 & 12.34 & 13.93 & 14.42 & 16.17 & 12.92 \\
Ash & 14.14 & 11.57 & 12.34 & 11.20 & 10.07 & 7.94 & 8.74 \\
Crude fiber & 5.51 & 5.94 & 6.23 & 6.57 & 6.68 & 9.69 & 7.81 \\
Nitrogen free extract & 30.45 & 35.41 & 36.55 & 35.03 & 36.23 & 33.26 & 38.42 \\
Chromic oxide & 0.48 & 0.51 & 0.47 & 0.46 & 0.48 & 0.51 & 0.49 \\
Gross energy (KJ/g) & 17.51 & 18.87 & 18.36 & 18.88 & 19.12 & 19.35 & 18.81 \\
P/E ratio* & 17.77 & 17.49 & 17.47 & 17.38 & 16.81 & 16.79 & 16.83 \\
\hline
\end{tabular}

* Protein to energy in mg protein per KJ (Kilo Joule) gross energy. 
Table 3. Formulation ( $\%$ dry matter basis) of the experimental diets used in the experiment.

\begin{tabular}{lccccccc}
\hline \multicolumn{1}{c}{ Ingredients } & \multicolumn{7}{c}{ Diets } \\
\cline { 2 - 8 } & $\begin{array}{c}\text { Diet 1 } \\
\text { (Control) }\end{array}$ & Diet 2 & Diet 3 & Diet 4 & Diet 5 & Diet 6 & Diet 7 \\
\hline Fish meal & 53.3 & 37.31 & 26.65 & 21.32 & 13.33 & - & - \\
Soybean meal & - & 9.06 & 12.08 & 12.08 & 18.12 & 15.11 & 24.17 \\
Mustard oilcake & - & 13.42 & - & - & - & 22.36 & - \\
Sesame oilcake & - & - & 19.6 & 19.6 & 14.7 & 24.5 & 29.4 \\
Linseed oilcake & - & - & 9.97 & 19.94 & 29.91 & 24.93 & 29.91 \\
Cod liver oil & 2.6 & 2.4 & 1.5 & 1.33 & 1.0 & 1.0 & 1.0 \\
Soybean oil & 2.6 & 2.4 & 1.0 & - & - & - & - \\
Wheat starch & 33 & 28.09 & 22.7 & 19.23 & 16.44 & 5.6 & 9.02 \\
Chromic oxide & 0.5 & 0.5 & 0.5 & 0.5 & 0.5 & 0.5 & 0.5 \\
Vitamin premix & 1.0 & 1.0 & 1.0 & 1.0 & 1.0 & 1.0 & 1.0 \\
Mineral premix & 1.0 & 1.0 & 1.0 & 1.0 & 1.0 & 1.0 & 1.0 \\
CMC & 2.0 & 2.0 & 2.0 & 2.0 & 2.0 & 2.0 & 2.0 \\
$\alpha$-cellulose & 4 & 2 & 2 & 2 & 2 & 2 & 2 \\
Total & 100.00 & 100.00 & 100.00 & 100.00 & 100.00 & 100.00 & 100.00 \\
\hline
\end{tabular}

Over all proximate composition of the dietary ingredients and diets were analyzed after AOAC (1980). Analysis of experimental data was done using the following formulae:

a. Weight gain $(\mathrm{g})=$ Mean final weight $(\mathrm{g})-$ mean initial weight $(\mathrm{g})$

b. $\%$ weight gain $=$

Mean final weight - mean initial weight

Mean initial weight

$\mathrm{X} 100$

c. Daily growth co-efficient $(\mathrm{DGC})=$

$100 \mathrm{X}\left(\mathrm{FBW}^{0.3333}-\mathrm{IBW}^{0.3333}\right)$

$\mathrm{t}$ (After Cowey, 1992)

(where, FBW = Final body weight, IBW = Initial body weight and $t=$ time in days)

d. Specific growth rate $(\mathrm{SGR})(\%$ per day $)=$

$\log _{\mathrm{e}} \mathrm{W}_{2}-\log _{\mathrm{e}} \mathrm{W}_{1}$

$$
\mathrm{T}_{2}-\mathrm{T}_{1}
$$

(After Castell \& Tiews, 1980)

(where, $\mathrm{W}_{1}=$ Initial live body weight in gram at time $\mathrm{T}_{1}$ and $\mathrm{W}_{2}=$ Final live body weight in gram at time $\mathrm{T}_{2}$ )

e. Food conversion ratio $(\mathrm{FCR})=$

Food fed (dry weight)

Live weight gain

X 100 (After Brown, 1957)

f. Protein efficiency ratio $($ PER $)=$

Live body weight (g)

(After Castell \& Tiews, 1980)

$\overline{\text { Crude protein fed (g) }}$

\section{Results and Discussion}

The degree of acceptance of each experimental diet was judged by a subjective behavioural observation of the feeding response. The fish fry readily consumed the feed and the degree of acceptability of all diets was more or less equal. No mortality of fish was observed and the fry were found more or less healthy throughout the study period. The growth responses and food utilization of fingerlings under different dietary treatments are presented in Table 4. The mean final weight, weight gain, specific growth rate (SGR), daily growth co-efficient (DGC) did not differ significantly $(\mathrm{P}<0.05)$ at termination of feeding trial of 56 days. From growth data it was observed that diet 7 containing $40 \%$ soybean meal (SBM), 30\% sesame oilcake (SOC) and $30 \%$ linseed oilcake (LOC) produced the best growth responses followed by diet 1 containing $100 \%$ fish meal (FM); diet 2 containing 70\% FM, 15\% SBM, and $15 \%$ mustard oilcake (MOC); diet 5 containing $25 \%$ FM, 30\% SBM, $15 \%$ SOC and 30\% LOC; diet 3 containing 50\% FM, 20\% SBM, 20\% SOC and $10 \%$ LOC and diet 4 containing 40\% FM, 20\% SBM, 20\% SOC and $20 \%$ LOC respectively. The lowest growth was found at diet 6 containing $25 \% \mathrm{SBM}, 25 \% \mathrm{MOC}$, $25 \%$ SOC and $25 \%$ LOC, but the growth responses were not significantly different from each other. Table 4 shows that Specific growth rate (SGR\%day) of various test diets ranges from 0.59 to 0.86 . Diet 7 showed the best SGR $(0.68)$ followed by diet $1(0.84)$, diet $2(0.83)$, diet $5(0.83)$, diet $4(0.68)$, diet $3(0.68)$ and diet $6(0.59)$ respectively. There was no significant difference $(\mathrm{P}>0.05)$ of SGRs among the diets, though diet 6 produced the lowest SGR among the experimental diets. Daily growth co-efficient (DGC) is the growth index, which is considered more appropriate for fish grown at constant temperature (Cowey, 1992) 
Table 4. Growth, food conversion, protein utilization, digestibility and weight gain of Labeo rohita under different test diet.

\begin{tabular}{lccccccc}
\hline \multicolumn{1}{c}{ Parameters } & \multicolumn{7}{c}{ Diet No. } \\
\cline { 2 - 8 } & 1 & 2 & 3 & 4 & 5 & 6 & 7 \\
\hline Initial weight (g) & 2.50 & 2.50 & 2.50 & 2.50 & 2.50 & 2.50 & 2.50 \\
Final weight (g) & 4.02 & 4.00 & 3.69 & 3.68 & 3.97 & 3.49 & 4.06 \\
Weight gain (g) & 1.52 & 1.50 & 1.16 & 1.22 & 1.48 & 0.99 & 1.55 \\
Weight gain (\%) & 61.00 & 59.87 & 46.59 & 48.63 & 59.18 & 39.68 & 62.05 \\
Daily growth co-efficient & 0.42 & 0.41 & 0.33 & 0.33 & 0.41 & 0.28 & 0.42 \\
SGR (\% per day) & & & & & & 0.59 & 0.86 \\
Total feed fed/fish (g) & 0.84 & 0.83 & 0.68 & 0.68 & 0.83 & 0.59 \\
FCR & 5.53 & 5.57 & 5.27 & 5.26 & 5.45 & 5.13 & 5.58 \\
PER & $3.69^{\mathrm{b}}$ & $3.73^{\mathrm{b}}$ & $4.66^{\mathrm{ab}}$ & $4.65^{\mathrm{ab}}$ & $3.73^{\mathrm{b}}$ & $5.22^{\mathrm{a}}$ & $3.61^{\mathrm{b}}$ \\
APD & 0.92 & 0.89 & 0.73 & 0.76 & 0.90 & 0.64 & 0.92 \\
& $77.79^{\mathrm{a}}$ & $73.63^{\mathrm{d}}$ & $74.10^{\mathrm{c}}$ & $72.38^{\mathrm{e}}$ & $70.55^{\mathrm{f}}$ & $74.58^{\mathrm{b}}$ & $73.58^{\mathrm{d}}$ \\
\hline
\end{tabular}

Figures in the same row with different superscripts are significantly different $(\mathrm{P}<0.05$; Duncan's test)

Diet 7 showed the best DGC followed by diet 1 , diet 2, diet 5, diet 4 and diet 3 respectively. The DGC of diet 6 was lowest. But the DGC values of different diets did not differ significantly. DGC values of different test diets varied from 0.28 to 0.42 .

The best result of total feed fed by fish was found in diet 7 (5.58) followed by diet 2 (5.57), diet 1 (5.53), diet 5 (5.45), diet 3 (5.27), diet 4 (5.26) and diet 6 (5.13) respectively. The lowest amount of feed fed (5.13) was in diet 6 . There was no significant difference $(\mathrm{P}>0.05)$ among the different diets. Food conversion ratio (FCR) of different diets ranged from 3.61 to 5.20. Diet 7 showed the best FCR (3.60) followed by diet 1, diet 5 , diet 2 , diet 4 and diet 3 . The FCR of diet 6 showed the lowest value (5.20). The FCR values were not significantly different $(\mathrm{P}>0.05)$ among the different diets. Protein efficiency ratio (PER) of different diets ranged from 0.642 to 0.92 . Diet 7 showed the best PER (0.92) followed by diet 5 , diet 2 , diet 4 and diet 3 respectively. The least PER value was in diet 6 . No significant difference $(\mathrm{P}>0.05)$ was observed among the diets. The apparent protein digestibility (APD) values of different diets ranged from 70.55 to 77.79 . Diet 7 showed the highest APD value (77.79) while diet 6 produced the lowest APD value (70.55). Similar APD value was found in diet 7 and diet 2 (73.63) that were significantly different from diet 3 , diet 4 and diet 5 .

Attempts to replace fishmeal with soybean meal, mustard oil cake, sesame oil cake and linseed oilcake in fish diet met with variable success. Improvement in diet processing technology is also reported to enhance the nutritional value of soybean for fish (Wee \& Shu, 1989). This evaluation, however, associated with fixed protein level originated from aforesaid oil cakes. The result of the present investigation indicated that average inclusion of soybean meal, sesame oil cake and linseed oil cake (40:30:30) showed better result than 100\% fishmeal inclusion. Though the inclusion of FM:SBM:MOC at 70:15:15 ratio showed the third rank but the inclusion of FM:SBM:SOC:LOC at 25:30:15:30 ratio showed the very nearer result to third one. Feed having FM:SBM:SOC:LOC at 40:20:20:20 ratio showed the nearer result to diet 4. At diet 3, FM:SBM:SOC:LOC at 50:20:20:10 ratio showed a lower performance. Fishmeal based diet have been known to yield higher growth in fishes, fishmeal being rich in all the dietary essential amino acid (Andrew \& Page, 1974). The lower growth performance in fishmeal based control diet compared with diets 2, 5, 3 and 4. In the present study may be attributed to the quality of the fishmeal used. It is known that the quality of fishmeal fluctuates accordingly to the origin and the season as well as processing method used (Ogino \& Chen, 1973). The lower growth rate of fish obtained by the present study with $100 \%$ fishmeal than the combination of oil seed cakes (SBM:SOC:LOC:: 40:30:30) might be due to the deficiency of any amino acid or acids or the inferior quality of fishmeal purchased. The FCR of the diet 7 was significantly different $(\mathrm{P}<0.05)$ and followed by diet 1,5 , and 2 respectively. The FCR value of diet 6 showed the lowest performance, which was followed by diet 3 and 4. Significant difference $(\mathrm{P}<0.05)$ was found among all the diets except diet 2 and 7 in terms of their apparent protein digestibility (APD) value though the value ranged from 70.55 to 77.79 .

The overall performance regarding the growth of fish fry of diet 7 was the best which was followed by diet 1,2, 5, 3 and diet 4 and lowest performance was found in diet 6 . This might be due to the presence of different oil cakes in diet 7 in which the amino acid profile was balanced by each other and for their bio- 
availability which could over come the antinutritional factors. The diet 1 (control diet), due to lack of amino acid might show a poorer performance than diet 7. A better trend was found in diet 5 but due to the presence of $15 \% \mathrm{MOC}$ at diet 2 and $25 \%$ at diet 6 showed poorer performances. This experiment was continued for 56 days in which the clear trend of the performance of different combination of different oil cake was not clear. Hereby, the role of other oilcakes is discussed, so that the different aspects of those might be taken into consideration.

Mustard oilcake was included at $25 \%$ inclusion level in diet 6 with SBM:SOC:LOC at 25:25:25 ratio showed the poor result, which did not produce growth comparable to soybean meal, sesame oilcake and linseed oilcake. This observation supported by the findings of Caper et al. (1982). The weight gain in this experiment showed a little variation in growth, several factors may be responsible for such growth. The factors are: more or less equal acceptability of the diets, different plant protein sources were combined in such a way to make up for any essential amino acid deficiency of each component of diet, presence of various toxic and antinutritional factors such as glucosinolate in mustard oilcake, phytic acid in sesame meal, linamarin in linseed oilcake, trypsin inhibitors, phytahaemagglutinins, phytic acid and its derivatives, saponins as well as phenolic compounds in soybean meal, imbalance of limiting essential amino acids in the diets containing higher inclusion of plant protein source, variations in the digestibility in the plant protein and carbohydrates and any negative influence of lack of light, presence of which might hamper the normal metabolic rate as well as growth of the fries. The poor growth responses of rohu fry fed diets containing mustard oilcake were presumably due to the presence of toxic components in the mustard seed, includes glucosinolates, which after hydrolysis by an enzyme thioglucosidase usually present in the seed, release highly toxic isothiocyanates (Gohi, 1981). Moreover, thioglucosidase may also act on glucosinolate to produce highly irritant mustard gas or intestinal irritants (Gohi, 1981). The mustard oilcake used in the evaluating investigation was in the form of expeller cake produced in Mymensingh town which was not heat treated and might have contain high levels of glucosinolates and isothiocyanate.

The performances of rohu fry fed diet $5(30 \%)$, diet 4 $(20 \%)$ and $3(10 \%)$ linseed oilcake protein were not significantly different $(\mathrm{P}>0.05)$ to that of fry receiving the control one i.e. diet 1 . In respect of growth, food conversion and protein utilization, the good performance of linseed meal in combination with other oilcakes but mustard oilcake attributed a better acceptability. As any specific trend was not found in this study which may enable to draw any specific finding so further continuation of the same trial should be carried out. The availability of well established information on the suitability of linseed meal as the alternative protein source is scanty. However, the efficiency of linseed oilcake as dietary protein supplement for domestic farm animals investigated extensively (Montgomery, 1980; Gohi, 1981; Mcdonald et al., 1981). Immature linseed may contain a small amount of cyanogenetic glucoside, linamarin which in the presence of an associated enzyme, linase, liberates hydrogen cyanide $(\mathrm{HCN})$ on hydrolysis. Unprocessed whole seeds and linseed oilcake processed under low temperature might be toxic to animals specially if wetted before being fed (Gohi, 1981; Mcdonald et al., 1981). Normal processing conditions involving high temperature treatment, however, destroys linase and most of the linamarin, and the resultant meal are quite safe (Gohi, 1981; Mcdonald et. al., 1981).

The sesame oilcake performed better role in $30 \%$ inclusion, but it was not significantly different from other diets, also having different inclusion level in different diets it could not show better results, despite of its good amino acid profile and any known toxic factor content (Gohi, 1981). Phytic acid, a phosphoric acid derivative (myoinositol-hexadihydrogen phosphate), has the capacity to bind di- and trivalent metal ions such as calcium, magnesium, zinc and iron to form insoluble salts (Liener, 1977; McDonald et al., 1981) and therefore rendering them unavailable during digestion (Liener, 1977; Smith, 1977). Though in diet 6, the inclusion level was $25 \%$ but it could not show better result due to the presence of $25 \% \mathrm{MOC}$ also. The ability of phytic acid to bind metal ions is lost when the phosphate groups are hydrolyzed through the action of the enzyme phytase (Liener, 1977). Although phytase activity has been shown to be present in ruminants (McDonald et al., 1981), animals like fish with simple stomach lack this enzyme in their gastrointestinal tracts (Lall, 1979). Therefore fish cannot utilize phytate bound phosphorus, or other metal ions. Unless phytic acid is already saturated with metal ions naturally present in the plant and sufficient mineral supplementation has not been used in the diet, mineral deficiency may occur. The requirements of carp and other fin fish for phosphorus, magnesium and zinc are well documented (Lall, 1979; Jauncey \& Ross, 1982). Therefore, the presence of a certain level of phytic acid in the sesame oilcake diet may have been a factor responsible for the average growth response of $L$. rohita fry. Sesame oilcake also has the poor palatability which 
may reduce the fish's food intake. Gohi (1981) reported that when sesame oilcake is wetted, it acquires an unpleasant taste and recommended that it should be kept dried when fed to animal. Essential amino acid deficiency may have another negative impact on growth of rohu fry. However, during processing of pelleted feed, the E-amino group of the lysine molecule may react with non-protein molecules present in the feed to form additional compounds that render lysine biologically unavailable although chemically measurable (Cowey, 1992).

The present evaluation indicated that a combination of different plant protein sources used as alternative for fish meal were more acceptable to $L$. rohita fry than plant protein materials used individually. However, the acceptability of the diet was influenced strongly by the inclusion of the combination of different plant protein sources.

\section{Reference}

Akand, A.M., Soeb, M., Hasan, M.R. \& Kibria, M.G. 1991. Nutritional requirements of Indian major carps, Labeo rohita(Hamilton)-1. Efect of dietary protein on growth, food conversion and body composition. Agriculture International. 1: 35-43.

Andrews, \& Page, J.W. 1974. Growth factor in the fish meal component of catfish diets. J. Nutri. 104: 1091-1096.

AOAC. 1980. Official method of analysis (ed. W. Horwitz). Association of Official Analytical Chemists (AOAC). $13^{\text {th }}$ edition. Washington D. C. $1018 \mathrm{pp}$.

Brown, M.E. 1957. Experimental studies on growth In: The physiology of fishes Vol. 1. (ed. Brown, M.E.). 361400pp. Academic Press, New York.

Capper, B.S., Wood J.F. \&. Jackson, A.J. 1982. The feeding value for carp of two types of mustard seed cake from Nepal. Aquaculture. 29: 373-377.

Castell, J.D. \& Tiews, K. 1980. Report of the EIFAC. IUCN and ICES working group on the standardization of methodoogy in fish nutrition research. Hamburg, Federal Republic of Germany. 21-23 March 1979, EIFAC Technical Paper No. 26.

Cowey, C.B. 1992. Nutrition: estimating requirements of rainbow trout. Aquaculture. 100: 177-189.

Gohi, B. 1981. Tropical feeds. Food and Agricultural Organisation (FAO) of the United Nations, Rome. $528 \mathrm{pp}$.
Hasan, M.R., Macintosh, D.J. \& Jauncey, K. 1997. Evaluation of some plant ingredients as dietary protein sources for common carp (Cyprinus carpio L.) fry. Aquaculture. 151: 55-70.

Jauncey, K. \& Ross, B. 1982. A Guide to Tilapia Feeds and Feeding. Institute of Aquaculture, University of Stirling, U.K. 111 pp.

Lall, S.P. 1979. Minerals in fin fish nutrition. In: Finfish Nutrition and Fish Feed Technology. Vol. I. (eds. Halver, J.E. and Tiews, K.), pp. 85-97. H. Heenemann $\mathrm{GmbH}$ and Co., Berlin.

Liener, I.E. Removal of naturally occurring toxicants. Adv. Chem. Ser. 160: 293-300.

Mcdonald, P., Edwards R.A. \& Green Halgh, J.F.D. 1981. Animal Nutrition. Longman. London and New York. $479 \mathrm{pp}$.

Montgomery, R.D. 1980. Cyanogens. In: Toxic Constituents in Plant Foodstuffs (ed. Liener, I. L.). pp. 143-160. Academic Press, New York.

Ogino, C. \& Chen, M.S. 1973. Protein nutrition in fish - III. Apparent and true digestibility of dietary protein in carp, Bull. Jap. Soc. Sci. Fish. 39: 649-651.

Reigh, K.C. \& Ellis, S.C. 1992. Effects of dietary soybean and fish protein ratios on growth and body composition of red drum (Sciaenops clarkii). Aquaculture. 104: 279-292.

Saad, C.R.B. 1979. Use of full-fat roasted soybeans in practical catfish diet. M.S. Thesis, Auburan University, U.S.A. 30 pp.

Smith, R.R. 1977. Recent research involving full-fat soybean meal in salmonid diets. Salmonid. 1: 8-18.

Tacon, A.G.J., Haaster, J.V., Featherstone, P.B., Kerr, K. \& Jackson, A.G. 1983. Studies on the utilization of full-fat soybean and solvent extracted soybean meal in complete diet for rainbow trout. Bull. Jpn. Soc. Sci. Fish. 49(9): 1437-1443.

Wassef, E.A. 1991. Development of diets for gilltead bream Sparus auratal cultured in Egypt. J. King Abdel Univ. Mar. Sci. 2: 101-109.

Wee, K.L. \& Shu, S.W. 1989. The nutritive value of boiled full-fat Soybean in pelleted feed for Nile tilapia. Aquaculture. 81: 303-314.

Manuscript received on 14.11.2007, accepted on 07.03.2008 